\title{
INITIAL CHARACTERIZATION OF NOVICE ENGINEERING DESIGNERS' CONSIDERATION OF CONTEXTUAL FACTORS
}

\author{
Burleson, Grace Ellen (1); \\ Herrera, Sean Vincent Salazar (2); \\ Toyama, Kentaro (3); \\ Sienko, Kathleen H. (2) \\ 1: Integrative Systems and Design, University of Michigan; \\ 2: Department of Mechanical Engineering, University of Michigan; \\ 3: School of Information, University of Michigan
}

\begin{abstract}
Engineering designers are encouraged to consider relevant contextual factors throughout their design processes. However, specific practices for incorporating context into design processes are lacking in the existing literature, and curricula related to the use of context during design processes is limited. As a preliminary step toward characterizing novice engineering designers' use of contextual factors, we qualitatively coded 10 mechanical engineering capstone design reports for contextual factors; half of the projects had domestic sponsors with varying themes, and the other half of the projects had international sponsors with a global health theme. Our findings showed that teams considered technological and institutional factors most frequently; other factors were considered less frequently. Global health themed design teams considered more contextual factors than non-global health themed teams. There was considerable variability among the contextual factors considered, as well as the stages during which they were considered. These outcomes have the potential to inform the development of pedagogical tools to support the acquisition of skills related to formally addressing context during engineering design processes.
\end{abstract}

Keywords: Contextual factors, Design education, Design engineering, Design methods

\section{Contact:}

Burleson, Grace Ellen

University of Michigan

Design Science

United States of America

gburl@umich.edu 


\section{INTRODUCTION}

Engineering education has historically focused on learning outcomes related to technical performance (Johnson et al., 2019; Leydens and Lucena, 2018), and there is a growing movement to incorporate learning experiences aimed at increasing students' awareness and consideration of broader contextual considerations, such as cultural, socio-technical, environmental, and economic factors (Christensen and Ernø-Kjølhede, 2012; Kyoung Ro et al., 2015; Neumeyer et al., 2013). For example, the U.S. engineering education Accreditation Board for Engineering and Technology (ABET) states that students must gain an ability to "make informed judgments, which must consider the impact of engineering solutions in global, economic, environmental, and societal contexts" (Accreditation Board for Engineering and Technology, 2020). However, the ways in which universities address the role of context in design are limited and vary considerably from program to program (Bielefeldt et al., 2017; Neumeyer et al., 2013). Thus, novice designers differ in their valuation of sociotechnical considerations (Johnson et al., 2019), breadth of contextual consideration during problem scoping (Atman et al., 2008), and ability to investigate contexts (Mohedas et al., 2014).

Very little prior work has investigated novice designer understanding and incorporation of contextual factors during design processes. Johnson et al. (2019) surveyed engineering students and determined that individual perceptions fall on a spectrum, with some acknowledging that social and environmental factors are inherently intertwined with technical factors, and others treating the technical component separate from social and environmental factors (Johnson et al., 2019). To investigate students' problem scoping design considerations, Bogusch et al. (2000) developed a framework with four components: (1) technical, (2) logistical, (3) natural, and (4) societal (Bogusch et al., 2000). The framework was used to determine students' considerations of detail- verses context-focused factors (Atman et al., 2008; Kilgore et al., 2007). However, it is still unknown how much novice designers consider specific contextual factors as they progress through a design process. In this paper, we report on an evaluation of final reports from a mechanical engineering capstone design course at a major U.S.-based university. Our study provides preliminary indications of what contextual factors were used and when they were used during novice engineering design processes.

\section{METHODOLOGY}

To begin investigating novice designer behaviors, our preliminary study was guided by the following research questions:

1. What contextual factors do novice mechanical engineering design teams incorporate into their design processes?

2. When do novice design teams incorporate contextual factors into their design processes?

\subsection{Capstone experience}

Our study investigated the incorporation of contextual factors (i.e., reported factors that mapped to design decisions) within mechanical engineering capstone design projects through the analysis of student teams' design review reports. At the university where this study was conducted, undergraduate mechanical engineering students were required to complete a capstone design course that included a single semester design project, typically in their fourth year. In this course, students were divided into teams of three to five members and assigned a unique project based on their project preferences. A variety of project topics were offered, but the majority involved a U.S.-based sponsor; approximately $20 \%$ of the projects had a global health theme with an institutional sponsor based in a low-income country. Project design briefs were developed by the lead course instructor based on input from project sponsors, which ranged in scope and application. The primary objective of the course was for students to "solve an open-ended mechanical engineering design problem including considerations of performance, cost, standards, and societal impact" (from the capstone course syllabus).

A subset of the students also completed an immersive global experiential learning experience during the summer preceding their enrolment in the capstone course (Sienko et al., 2018). This immersive experience included two months of preparatory training in the United States, followed by 6-8 weeks at the sponsoring institution. Since designer contextual experience has been shown to influence perceptions and behavior during design processes (Hu and Reid, 2018), we specifically included reports from both global health and non-global health themed design projects, acknowledging that 
students working on U.S. projects likely have more familiarity of project context than those working in global contexts.

\subsection{Data collection}

A stratified de-identified set of global health ("A") and non-global health ("B") themed design reports was obtained $(n=52)$. Five reports from each group were randomly selected (Table 1). The University of Michigan's Institutional Review Board determined unregulated status due to the use of a deidentified secondary dataset (HUM00176110).

Table 1. Projects included in this analysis.

\begin{tabular}{|l|l|l|l|}
\hline Team & Project in a low-income country & Team & Project in the U.S. \\
\hline A1 & Surgical device & B1 & Vehicle sub-system \\
\hline A2 & Obstetric device & B2 & Manufacturing equipment \\
\hline A3 & Rehabilitation device & B3 & Lab equipment \\
\hline A4 & Rehabilitation device & B4 & Testing equipment \\
\hline A5 & Therapeutic device & B5 & Waste management equipment \\
\hline
\end{tabular}

\subsection{Data analysis}

The set of ten final design reports were reviewed and coded for contextual factors identified by a taxonomy of nine contextual categories (Aranda-Jan et al., 2016). Contextual factors are attributes that depend on their specific location or setting, which sometimes greatly influence technical parameters and design decisions (Aranda-Jan et al., 2016). The reports were deductively coded for the contextual factors listed and defined in Table 2 by two study team members (inter-rater reliability of 0.88). For each coded excerpt, the corresponding design stage was noted (problem scoping, requirements and specifications, concept generation, concept selection, refinement, or verification and validation). Excerpts within each contextual factor category were reviewed and themes within were synthesized (i.e., stages within the design processes, impact on design decisions and features, etc.) as part of an iterative thematic analysis performed by all study team members.

Table 2. Codebook of contextual factor categories used for data analysis adapted from (Aranda-Jan et al., 2016).

\begin{tabular}{|l|l|l|}
\hline Contextual codes & Definition & $\begin{array}{l}\text { Examples of } \\
\text { contextual factors }\end{array}$ \\
\hline Industrial & $\begin{array}{l}\text { External functional factors required for performance and } \\
\text { operability, such as those relating to supply chain }\end{array}$ & $\begin{array}{l}\text { Maintenance, } \\
\text { manufacturing, supply }\end{array}$ \\
\hline Technological & $\begin{array}{l}\text { Factors that drive the performance of the artifact for } \\
\text { adequate operability and functionality within its } \\
\text { implementation setting }\end{array}$ & $\begin{array}{l}\text { Interoperability, } \\
\text { relevant, standards }\end{array}$ \\
\hline Infrastructural & $\begin{array}{l}\text { External factors needed for functionality and operability } \\
\text { within the location-specific built environment }\end{array}$ & Utility, roads \\
\hline $\begin{array}{l}\text { Geographical \& } \\
\text { Environmental }\end{array}$ & $\begin{array}{l}\text { External factors needed for functionality and operability } \\
\text { within the location-specific natural environment }\end{array}$ & Temperature, humidity \\
\hline Institutional & $\begin{array}{l}\text { Factors related to the organization or institution for } \\
\text { which the artifact is intended to operate in. }\end{array}$ & $\begin{array}{l}\text { Operational resources, } \\
\text { staff }\end{array}$ \\
\hline Economic & $\begin{array}{l}\text { Factors related to economic capacity, structures, and } \\
\text { individual and household attributes }\end{array}$ & $\begin{array}{l}\text { Income level, } \\
\text { purchasing power }\end{array}$ \\
\hline Political & $\begin{array}{l}\text { Factors related to the political structures and socio- } \\
\text { political organization of the context }\end{array}$ & Subsidies, corruption \\
\hline Public Health & $\begin{array}{l}\text { Factors related to the health status of the population and } \\
\text { location-specific conditions and priorities }\end{array}$ & $\begin{array}{l}\text { Prevalence of disease, } \\
\text { body characteristics }\end{array}$ \\
\hline Socio-Cultural & $\begin{array}{l}\text { Factors related to the context-specific characteristics of } \\
\text { the population }\end{array}$ & $\begin{array}{l}\text { Language, beliefs, } \\
\text { traditions }\end{array}$ \\
\hline
\end{tabular}




\section{RESULTS}

\subsection{Overview}

According to their design reports, all teams $(n=10)$ incorporated technological and institutional contextual factors to varying degrees into their design processes. Seven teams incorporated industrial factors, six teams incorporated public health factors, four teams incorporated economic factors, and four teams incorporated infrastructural factors into their design processes. Three teams incorporated geographical and environmental factors and three incorporated socio-cultural factors into their design processes, however, no teams incorporated political factors. Overall, the global health design teams incorporated more contextual factors compared to the non-global health teams, particularly factors within the industrial, public health, and economic categories. Table 3 presents a summary of contextual factors described in the design reports.

Table 3. Contextual factors identified in global health $(A)$ and non-global health $(B)$ reports.

\begin{tabular}{|c|c|c|c|}
\hline \multirow[b]{2}{*}{ Contextual codes and factors } & \multicolumn{3}{|c|}{ Number of reports } \\
\hline & \begin{tabular}{|l|} 
Total \\
$\mathrm{n}=10$
\end{tabular} & $\begin{array}{l}\mathrm{A} \\
\mathrm{n}=5\end{array}$ & $\begin{array}{l}\mathrm{B} \\
\mathrm{n}=5\end{array}$ \\
\hline Technological & 10 & 5 & 5 \\
\hline Available technologies in context & 7 & 5 & 2 \\
\hline Compatibility within the technical context & 3 & 1 & 2 \\
\hline Context-specific quality, testing, or technical standards & 2 & 1 & 1 \\
\hline Availability of consumables & 2 & 1 & 1 \\
\hline Institutional & 10 & 5 & 5 \\
\hline Existing practices and procedures & 8 & 5 & 3 \\
\hline Institutional financial capacity & 6 & 2 & 4 \\
\hline Capacity and capability of institutional staff & 5 & 3 & 2 \\
\hline Available resources and space within the institution & 5 & 2 & 3 \\
\hline Industrial & 7 & 5 & 2 \\
\hline Quality and availability of manufacturing processes & 5 & 5 & 1 \\
\hline Availability of materials & 4 & 4 & 1 \\
\hline Type and availability of maintenance & 4 & 2 & 1 \\
\hline Public Health & 6 & 5 & 1 \\
\hline Quality, capacity, or availability of local healthcare & 3 & 3 & 0 \\
\hline Health demographics and physiological characteristics & 3 & 2 & 1 \\
\hline Infrastructural & 4 & 3 & 1 \\
\hline Availability of utility & 2 & 2 & 0 \\
\hline Quality of municipal infrastructure (e.g., roads) & 2 & 1 & 1 \\
\hline Economic & 4 & 3 & 1 \\
\hline End user income-level & 3 & 2 & 1 \\
\hline Country-level economic classification & 1 & 1 & 0 \\
\hline Geographical \& Environmental & 3 & 2 & 1 \\
\hline Environmental conditions (e.g., temperature, humidity) & 3 & 2 & 1 \\
\hline Socio-Cultural & 3 & 2 & 1 \\
\hline Education demographics & 2 & 1 & 1 \\
\hline Race-based characteristics and traits & 1 & 1 & 0 \\
\hline Political & 0 & 0 & 0 \\
\hline
\end{tabular}

\subsection{Considerations of contextual factors during design stages}

Teams described contextual factors throughout most stages of their design processes, as illustrated in Figure 1. The one exception was the 'concept generation' stage, during which none of the teams explicitly noted context. The remaining findings are ordered according to these design stages. 


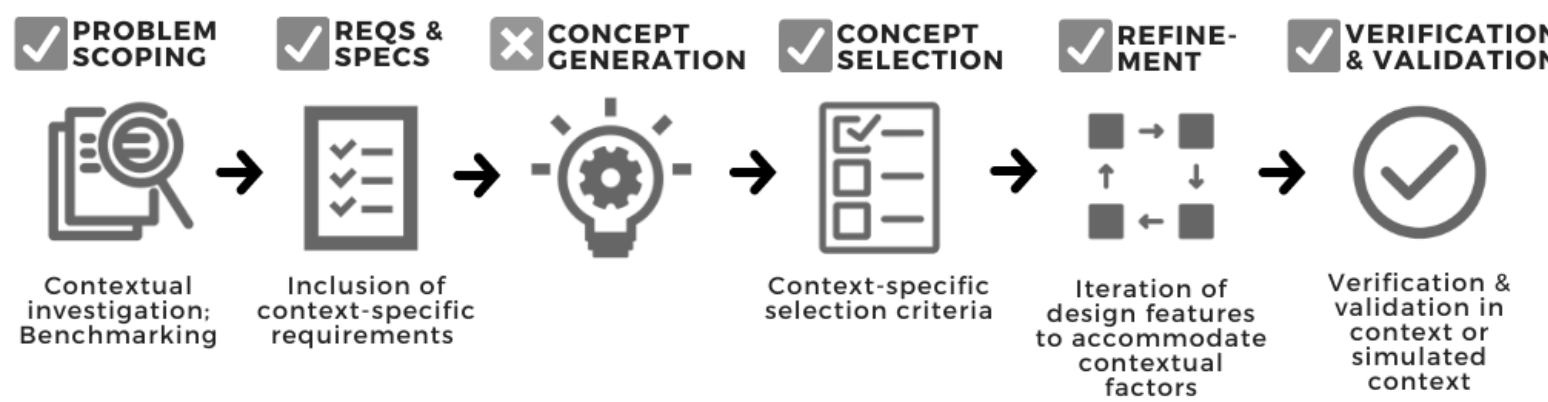

Figure 1. Common design process stages during which student teams incorporated contextual factors (note: no contextual factors were mentioned during 'concept generation').

\subsubsection{Problem scoping}

After receiving project design briefs from the lead instructor, all teams initiated problem scoping activities that involved information gathering via stakeholder interviews, observations, and secondary research. It should be noted that many contextual factors that were cited in the problem scoping stages primarily served to motivate and define the design scope and did not necessarily correlate to specific design decisions. In their reporting, eight teams discussed contextual factors during their problem scoping stages.

Two design teams (A2, B1) described technological contextual factors related to their artifacts' compatibility within its technical context during problem scoping, e.g., "the device must also be compatible with the [...] trolleys" (A2). Three reports (A1, A3, B2) discussed institutional practices and procedures during their problem scoping work, e.g., current practices for physical therapy (A3), to motivate and scope their problem. Three design teams (A1, A3, A4) included broad claims regarding contextual factors related to quality, capacity, or availability of local health care, e.g., a "higher rate of epidural failures in [their country] compared to the U.S. and Europe" (A1), and a lack of available care since "health care centers are at or over capacity" (A4).

During problem scoping, teams were required to conduct benchmarking research to understand existing technological solutions. During benchmarking activities, seven teams mentioned contextual factors when assessing existing solutions' abilities or inabilities to meet their evolving context-specific technical requirements. All five global health teams discussed the currently available solutions for the problem in their specific country of use compared to the U.S. or countries in Europe. B2 briefly listed devices available within their specific context-of-use that met similar needs, but not fully the needs of their stakeholder, and B5 considered the different available solutions for large-scale (public) vs. smallscale (household) contexts.

\subsubsection{Requirements and specifications}

All ten teams included at least one context-specific requirement, suggesting that this is a design stage when novice designers appropriately emphasize contextual factors. Overall, 39 context-specific requirements were included across the sample of reports, with the majority primarily categorized as institutional $(n=20)$, followed by industrial $(n=6)$, economic $(n=3)$, infrastructure $(n=3)$, technological $(\mathrm{n}=1)$, public health $(\mathrm{n}=4)$, socio-cultural $(\mathrm{n}=1)$, geographical/environmental $(\mathrm{n}=1)$. Notably, contextual factors that were more easily quantifiable (e.g., measurable in cost, size, duration, etc.) were more often incorporated into requirements than those that were more qualitative in nature. For example, although six teams considered industrial factors (e.g., manufacturing, material availability, and maintenance), less than half of the coded industrial contextual factors were incorporated in those teams' requirements.

\subsubsection{Concept selection and refinement}

Five teams reported contextual factors during their concept selection stage. Three teams described the impact of operating within context-specific environmental conditions (e.g., temperature, humidity, etc.) during concept selection and refinement, e.g., selecting materials to withstand the area's tropical climate (A2) and selecting geometries to withstand high wind speeds in the region (B5).

Seven design teams reported contextual factors during their design refinement stage, e.g., feedback from a project stakeholder encouraged A4 to change their final design to accommodate more readily 
available materials, such that the artifact could be more easily manufactured in the intended context. To account for compatibility with the technological context, B2 refined specific features (in this case, adjustable straps) that could "accommodate many more types of [components] that [the sponsor] produces" and, although it was not listed as a requirement, A5 described that "a hinged door was added [... for] removal of the external garment for [the institution's] sanitation purposes."

\subsubsection{Verification and validation}

The verification and validation stage was another point where contextual factors figured prominently. All teams confirmed whether or not their solutions met context-related requirements and specifications to some extent. In a few cases, teams verified the context-of-use either physically (e.g., B3 verified that the artifact "fits within the size constraints" at the institution) or virtually (e.g., B2 created a simulation in CAD to assess the feasibility of their design within their intended context-of-use, which was a specific manufacturing plant).

Some teams included new contextual factors that had not yet been considered in prior sections of their report. For example, A1 and A3 confirmed the availability of materials in their respective context-ofuse by interviewing local stakeholders; however, this contextual factor had not been mentioned earlier in A1's report.

Two design teams (A1, A3) discussed the importance of needing to verify their selected design concepts and continue to develop their solution related to the technological context (e.g., perform well with current solutions within the context-of-use). However, both teams claimed they were unable to complete verification in the context-of-use due to accessibility, since neither team was able to travel to their project's intended context-of-use (i.e., specific institutions in Africa). Some teams acknowledged that they lacked enough contextual information to verify specific requirements. For example, A3 reported, "validation of the 'Affordability' requirement was unable to be completed due to the team's incomplete knowledge of context-relevant pricing of materials and manufacturing processes."

\subsubsection{Technological, testing, and quality standards}

Since all teams were required to consider relevant standards, all design teams considered and incorporated technological, testing, or quality standards during various stages in their design processes. Notably, only one global health team referenced a context-specific standard (A2 incorporated a requirement based on a country-specific health mandate for infection prevention via equipment cleaning). A4 was the only global health team to claim that a different standard would need to be considered in future work stating, "when manufacturing in [country], ISO will be the standard for the metric drawings instead." Two global health teams (A3, A5) explicitly claimed that there were no context-specific standards that applied to their design contexts.

\section{DIScussion}

\subsection{Prioritizing technical and distancing from social considerations}

Though preliminary, our findings suggest that engineering students tend to focus their attention on contextual factors "closest" to the technological artifact, including technological, institutional, and industrial contextual factors (Table 3); all teams incorporated technological and institutional factors to some degree. In contrast, "further" contextual factors, including political, socio-cultural, environmental, and economic contextual factors were rarely mentioned in the teams' design documentation. By using the word "closest," we intend to invoke a sense of physical or social proximity that also correlates with the frequency of interaction. Institutional policies and practices often impinge directly and frequently on a technology's use, whereas political issues may appear to only have an indirect or infrequent effect. Engineering education in the U.S. emphasizes these "closer" technical details over broader social considerations (Leydens and Lucena, 2018).

Industrial factors were incorporated by all global health themed teams and only two non-global health themed teams, which may be a reflection of the lack of emphasis on design for manufacturing in capstone experiences (Howe et al., 2018). Furthermore, although literature emphasizes the importance of maintenance planning in the design of global health-related products (Burleson and Sharp, 2018), the three global health teams that considered this contextual factor did so in different ways (e.g., cleanability, serviceability, and durability), suggesting that students may benefit from additional 
support to incorporate more broad maintenance-related factors into their engineering design decisionmaking.

The limited number of teams that incorporated socio-cultural, environmental, and infrastructure, and political factors into their design processes suggests that students either perceived the factors to be outside the scope of their project (which may or may not be true), were not encouraged to incorporate these factors into their design processes, opted not to address these factors, and/or did not know how to incorporate these factors into their design processes. Ongoing research suggests that engineering students in the U.S. do not perceive social and environmental considerations to have the same significance as technical factors (Johnson et al., 2019) and experience difficulty justifying the value and relevance of "nontechnical work" (Niles et al., 2020).

Importantly, none of the teams' reports described political factors in any manner. Although our data does not allow us to explore motivations for the exclusion of political factors, literature suggests that engineering students in the U.S. perceive politics to be positioned at the periphery of engineering practice (Morgan et al., 2020). The lack of these factors in the subset of reports coded as part of this study may be a reflection of the lack of political emphasis within engineering education overall. These findings support the need for additional research to understand novice engineering design behaviors and the development of pedagogy to support the use of these relevant, yet under-prioritized, contextual factors.

\subsection{Discrepancy when incorporating contextual factors during design}

Contextual factors were considered during all but one stage ('concept generation') of the teams' design processes, with the most frequent occurrences during the development of requirements and specifications, and during verification and validation. Furthermore, there was considerable variability in the ways contextual factors were incorporated across specific stages. For example, although five teams incorporated the industrial contextual factor 'availability of materials,' each team did so in different ways, e.g., comparing available material quality of their international context with U.S.-based materials during problem scoping (A2), developing a requirement that materials must be "available in context" (A3, A4), selecting a final concept based on the availability of materials (A1, B4), and verifying if the selected materials were available in their intended context (A1, A3). This salient example highlights the variability with respect to how teams in this study incorporated a similar contextual factor during different stages in their design processes.

In a subset of the reports, some contextual factors emerged during the later stages of teams' design processes that were not mentioned during their earlier design stages. For example, concept selection criteria and refinement of artifact features that considered previously unmentioned contextual factors. This finding suggests that student teams may be learning about additional contextual factors as their designs progress, may have struggled to incorporate a more complete set of contextual factors into their requirements, or may not be as deliberate in their documentation of relevant contextual factors compared to other more-documented elements (e.g., technical requirements) in their reports.

\subsection{Designers' contextual experience: considering the U.S. context as the baseline}

In our study, teams working on projects with domestic sponsors incorporated fewer contextual factors than students working on projects with international sponsors. We posit that teams less familiar with their designed artifacts' use settings may have been further motivated to investigate and incorporate contextual factors during their design processes. Teams with more familiarity with their designed artifacts' uses settings may have assumed knowledge about their use settings, potentially resulting in the application of implicit contextual information into their design processes. Additionally, teams working on the global health themed projects often compared the contextual factors relevant to the targeted use settings of their design artifacts to analogous contextual factors in the U.S., suggesting that the U.S. context served as a baseline for all teams. Prior work has identified a correlation between designers' contextual experience and their selection and application of design methods (Chou, 2020), however, a correlation between designers' contextual experience and the quality of their design outcomes has yet to be determined (Hu and Reid, 2018). Nonetheless, our study suggests that there may be relationships between designers' contextual experiences and the incorporation of contextual factors into their design processes. Further investigation into the role of the designer's prior contextual experience and identity and its influence on investigation and incorporation of contextual factors during design processes is therefore suggested. 


\subsection{Role of stakeholder engagement}

Stakeholder engagement during engineering capstone courses has been identified as a distinguishing characteristic of highly-ranked engineering programs since it provides additional learning opportunities for novice engineers (Ward, 2013). At the university where this study was conducted, instructors emphasized the importance of stakeholder engagement during design processes and students were encouraged to meet and interview stakeholders from the project's sponsoring institution. Encouragement from instructors (i.e., lecture content, project mentorship, grading rubric referencing context assessment) likely heavily influenced teams and contributed to the notable incorporation of institutional contextual factors by all teams to some extent, e.g., practices/procedures at the institution ( 8 teams), institutional financial capacity (6 teams), staffing capacity and/or capability (5 teams), and available resources and space within the institution (5 teams). Emphasis on institutional stakeholder engagement may have also contributed to the disproportionate (20 of the identified 39 context-specific requirements) incorporation of contextual factors from the institutional category.

Ongoing research advocates for diverse stakeholder input as a way to increase the breadth of contextual information gathered during design processes, e.g., engaging with: government stakeholders to assess economic and political constraints, corporations to assess infrastructure and industrial constraints, and individual users to assess socio-cultural and technological constraints (Jagtap and Larsson, 2019). Increasing the diversity and breadth of stakeholder input may provide novice designers with additional opportunities to investigate and include a wider array of contextual factors during their design processes. However, historically, engineering education has not emphasized qualitative research methodologies, and therefore, students may have had limited and/or variable experience with gathering and synthesizing qualitative data (e.g., interview and observation data) from engagements with stakeholders, and applying the information to their design decisions. As previously mentioned, a subset of design team members received some formal training in the use of design ethnography methodologies prior to completing their immersive global experiential learning experience and had an opportunity to practice those skills at their international sponsors' institutions prior to the capstone course, which may have accounted for some of the variability observed across teams in this study. Pedagogy focused on the acquisition and analysis of qualitative data may affect the quantity and quality of incorporation of contextual factors into students' design processes.

\subsection{Limitations}

We acknowledge that this study was limited in size and scope, with a review of 10 randomly selected student team reports at a single university; these preliminary findings were not confirmed through interviews or other forms of primary data. Teams likely did not fully document all instances during which they considered context within their respective design processes, thus, contextual factors that were less deliberately incorporated or considered latent may not be included in these findings.

\section{CONCLUSION}

Our findings highlighted the variability among undergraduate engineering design student teams' incorporation of contextual factors during capstone design projects. In general, teams most frequently considered technological and institutional factors and neglected other contextual factors, particularly economic, environmental, socio-cultural, and political factors. Contextual factors were most frequently incorporated into teams' requirements and specifications. Additionally, teams were more likely to incorporate contextual factors with quantitative elements than factors that were more qualitative in nature, suggesting that additional support for collection, synthesis, and application of qualitative information may benefit novice designers' incorporation of contextual factors throughout their design processes. Teams with international institutional sponsors within our sample (i.e., global health themed projects) often treated the U.S. context as a baseline and incorporated more contextual factors overall throughout their design processes than teams with U.S. institutional sponsors, suggesting that teams pursuing projects with less familiar contexts may be more motivated to practice contextual investigation and incorporate contextual factors during their design processes. Furthermore, our outcomes suggest that emphasis on engagement with broader groups of stakeholders may be one way to increase consideration and incorporation of contextual factors during design processes. The findings from this preliminary study have the potential to inform the development of pedagogical tools to support the acquisition of skills related to incorporating contextual factors into novice engineering design processes. 


\section{REFERENCES}

Accreditation Board for Engineering and Technology. (2020), “ABET Requirements”, available at: https://www.abet.org/accreditation/accreditation-criteria/criteria-for-accrediting-engineering-programs2020-2021/.

Aranda-Jan, C.B., Jagtap, S. and Moultrie, J. (2016), “Towards A Framework for Holistic Contextual Design for Low-Resource Settings", International Journal of Design, Vol. 10 No. 3, pp. 43-63.

Atman, C.J., Yasuhara, K., Adams, R.S., Barker, T.J., Turns, J. and Rhone, E. (2008), "Breadth in problem scoping: A comparison of freshman and senior engineering students", International Journal of Engineering Education, Vol. 24 No. 2, pp. 234-245.

Bielefeldt, A.R., Polmear, M., Knight, D., Swan, C. and Canney, N. (2017), "Ethics Across the Curriculum? Integrating Ethics and Societal Impact Topics into Core Engineering Courses", Proceedings of the ASEE American Society for Engineering Education Rocky Mountain Section Conference, No. September, pp. 1-15.

Bogusch, L.L., Turns, J. and Atman, C.J. (2000), "Engineering design factors: How broadly do students define problems?", Proceedings - Frontiers in Education Conference, Vol. 2, IEEE, available at:https://doi.org/10.1109/fie.2000.896664.

Burleson, G. and Sharp, K. (2018), "Comparative Study of Maintenance Planning and Failure Modes of Drinking Water Projects: Case Studies from Eastern Uganda”, IEEE Global Humanitarian Technology Conference, available at:https://doi.org/10.1109/GHTC.2018.8601897.

Chou, S.L. (2020), Exploring “Designer Context” in Engineering Design: The Relationship Between Self, Environment, and Design Methods, University of Michigan, available at: https://deepblue.lib.umich.edu/handle/2027.42/163100.

Christensen, S.H. and Ernø-Kjølhede, E. (2012), "Socio-technical Integration in Engineering Education: A Never-Ending Story”, Engineering, Development and Philosophy, Springer, Dordrecht, pp. 197-213.

Howe, S., Rosenbauer, L., Dyke Ford, J., Alvarez, N., Paretti, M., Gewirtz, C., Kotys-Schwartz, D., et al. (2018), Preliminary Results from a Study Investigating the Transition from Capstone Design to Industry, 2018 Capstone Design Conference Proceedings.

Hu, W.L. and Reid, T. (2018), "The Effects of Designers Contextual Experience on the Ideation Process and Design Outcomes", Journal of Mechanical Design, Transactions of the ASME, American Society of Mechanical Engineers (ASME), Vol. 140 No. 10, available at:https://doi.org/10.1115/1.4040625.

Jagtap, S. and Larsson, T. (2019), "Resource-Limited Societies, Integrated Design Solutions, and Stakeholder Input", She Ji, Tongji University Press, Vol. 5 No. 4, pp. 285-303.

Johnson, K., Leydens, J.A., Walter, J., Boll, A.M., Claussen, S. and Moskal, B.M. (2019), "Sociotechnical habits of mind: Initial survey results and their formative impact on sociotechnical teaching and learning", ASEE Annual Conference and Exposition, Conference Proceedings, available at:https://doi.org/10.18260/1-2-33275.

Kilgore, D., Atman, C.J., Yasuhara, K., Barker, T.J. and Morozov, A. (2007), “Considering Context: A Study of First-Year Engineering Students", Journal of Engineering Education, Wiley-Blackwell Publishing Ltd, Vol. 96 No. 4, pp. 321-334.

Kyoung Ro, H., Merson, D., Lattuca, L.R. and Terenzini, P.T. (2015), "Validity of the Contextual Competence Scale for Engineering Students", Journal of Engineering Education, Wiley-Blackwell Publishing Ltd, Vol. 104 No. 1, pp. 35-54.

Leydens, J.A. and Lucena, J.C. (2018), "Humanities and Social Sciences in Engineering Education: From Irrelevance to Social Justice", Engineering Justice: Transforming Engineering Education and Practice, IEEE, pp. 155-195.

Mohedas, I., Daly, S.R. and Sienko, K.H. (2014), "Design Ethnography in Capstone Design: Investigating Student Use and Perceptions", International Journal of Engineering Education, Vol. 30 No. 4, pp. 888-900.

Morgan, D.L., Davis, K.B. and López, N. (2020), "Engineering political fluency: Identifying tensions in the political identity development of engineering majors", Journal of Engineering Education, Wiley-Blackwell Publishing Ltd, Vol. 109 No. 1, pp. 107-124.

Neumeyer, X., Chen, W. and McKenna, A.F. (2013), "Embedding Context in Teaching Engineering Design”, Advances in Engineering Education, Vol. 3 No. 4, pp. 1-19.

Niles, S., Contreras, S., Roudbari, S., Kaminsky, J. and Harrison, J.L. (2020), "Resisting and assisting engagement with public welfare in engineering education", Journal of Engineering Education, WileyBlackwell Publishing Ltd, Vol. 109 No. 3, pp. 491-507.

Sienko, K.H., Young, M.R., Kaufmann, E.E., Obed, S., Danso, K.A., Opare-Addo, H.S., Odoi, A.T., et al. (2018), "Global health design: Clinical immersion, opportunity identification and definition, and design experiences”, International Journal of Engineering Education, Vol. 34 No. 2(B).

Ward, T.A. (2013), "Common elements of capstone projects in the world's top-ranked engineering universities", European Journal of Engineering Education, Taylor \& Francis, Vol. 38 No. 2, pp. 211-218. 


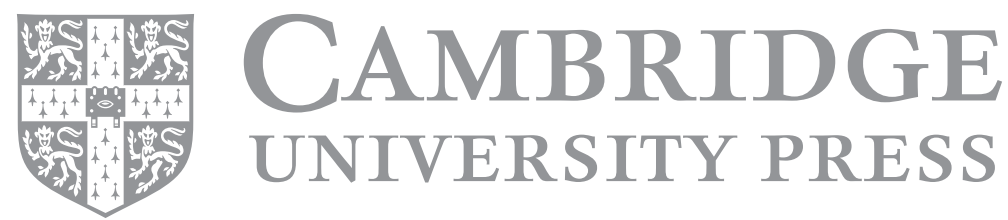

